\title{
Infectious diseases on a general internal medicine clinical teaching unit
}

\author{
LE Nicolle MD FRCPC ${ }^{1}$, J Uhanova $M^{2}{ }^{2}$, P Orr MD FRCPC $^{1}$, A Kraut MD FRCPC $^{2}$, \\ K Van Ameyde MD FRCPC ${ }^{2}$, G Dow MD FRCPC ${ }^{1}$
}

\begin{abstract}
LE Nicolle, J Uhanova, P Orr, A Kraut, K Van Ameyde, G Dow. Infectious diseases on a general internal medicine clinical teaching unit. Can J Infect Dis 1999;10(1):33-38.

OBJECTIVE: To describe the spectrum of infectious diseases and characteristics of patients admitted with infections on a general internal medicine clinical teaching unit.

DESIGN: Retrospective review of patients admitted to one general internal medicine unit at a tertiary care teaching hospital during two three-month periods.

METHODS: Data collection through chart review.

OUTCOME MEASURES: Descriptive analysis of types of infections: therapeutic interventions; consultations and outcomes, including death; hospital-acquired infection; and length of stay.

RESULTS: During the two three-month periods, 76 of 233 (33\%) and 52 of 209 (25\%) admissions were associated with a primary diagnosis of infection. An additional $23(10 \%)$ and $24(12 \%)$ patients had infection at the time of admission, but this was not the primary admitting diagnosis. Pneumonia, urinary infection, and skin and soft tissue infection were the most frequent diagnosis at the time of admission, but these accounted for only about $50 \%$ of admissions with infection. Patients admitted with infection were characterized by a younger age, greater number of therapeutic interventions in the first $24 \mathrm{~h}$, and increased medication costs, entirely attributable to antimicrobial therapy, but patients admitted with infection did not differ in comorbidity, death, nosocomial infection or length of stay compared with patients without infection. CONCLUSIONS: A wide variety of infections contribute to admissions to general internal medical clinical teaching units. Patients with infection have more interventions and an increased cost of care, but do not differ in outcome.
\end{abstract}

Key Words: Antimicrobial use, Clinical teaching units, Infections, Internal medicine

Maladies infectieuses dans une unité d'enseignement clinique de médecine interne générale

OBJECTIF : Décrire le spectre des maladies infectieuses et les caractéristiques des patients admis avec des infections dans une unité d'enseignement clinique de médecine interne générale.

MODÈLE : Étude rétrospective des patients admis dans une unité de médecine interne générale dans un hôpital universitaire de soins tertiaires pendant deux périodes de trois mois.

MÉTHODES : Collecte des données par l'examen des dossiers.

MESURES DES RÉSULTATS : Analyse descriptive des types d'infections; des interventions thérapeutiques, des consultations et de l'évolution comprenant le décès, les infections nosocomiales et la durée du séjour hospitalier.

RÉSULTATS : Pendant les deux périodes de trois mois, 76 des 233 (33\%) et 52 des 209 (25\%) admissions étaient associées à un diagnostic principal d'infection. Vingt-trois patients $(10 \%)$ et 24 patients (12\%) supplémentaires

voir page suivante

Sections of ${ }^{1}$ Infectious Diseases and ${ }^{2}$ General Internal Medicine, Department of Internal Medicine, University of Manitoba,

Winnipeg, Manitoba

Correspondence: Dr LE Nicolle, Health Sciences Centre, GC430-820 Sherbrook Street, Winnipeg, Manitoba R3A 1R9.

Telephone 204-787-7772, fax 204-787-4826, e-mail nicolle@cc.umanitoba.ca

Received for publication January 17, 1998. Accepted April 12, 1998 
accusaient une infection au moment de l'admission, mais qui ne constituait pas la cause principale d'admission. Une pneumonie, une infection urinaire, une infection cutanée et des tissus mous étaient les diagnostics les plus fréquents au moment de l'admission, mais ces cas comptaient seulement pour environ $50 \%$ des patients admis avec une infection. Les caractéristiques des patients admis avec une infection étaient un âge plus jeune, un nombre plus élevé d'interventions thérapeutiques dans les premières 24 heures, et une augmentation du coût des médicaments entièrement attribuable au traitement antibactérien, mais les patients admis avec une infection n'étaient pas différents des patients non infectés sur le plan de la comorbidité, de la mortalité, des infections nosocomiales ou de la durée du séjour hospitalier.

CONCLUSIONS : Une grande variété d'infections contribuent aux admissions dans les unités d'enseignement clinique de médecine interne générale. Les interventions auprès des patients infectés sont plus nombreuses et le coût des soins plus élevé, mais l'évolution clinique est la même.

I Canadian teaching hospitals, the clinical teaching unit (CTU) delivers general internal medicine in-patient care and is the principle in-patient forum for postgraduate internal medicine training programs (1). Residents in internal medicine receive most of their clinical training about in-patient infectious diseases through the care of patients admitted to these units. An understanding of the infectious diseases experienced by patients on these units is important for evaluating the infectious diseases educational experience of postgraduate trainees on the general medical ward. In addition, information regarding the use of in-patient beds for infectious diseases is useful to the planning of optimal programs in health care delivery to this patient population.

The University of Manitoba Department of Medicine (Winnipeg, Manitoba) has five general medical clinical teaching units, three at the Health Sciences Centre and two at St Boniface Hospital. In 1995, during two three-month periods, we prospectively collected data for all patients admitted to one of the units at the Health Sciences Centre to describe the patient population and the care provided. In this paper, we discuss observations relevant to infectious diseases in the population of patients admitted to the CTUs during the two study periods.

\section{PATIENTS AND METHODS}

Institutional characteristics: The Health Sciences Centre is an 830-bed tertiary care referral and teaching hospital, and the largest acute care institution in Manitoba. In addition to providing referral care for the province, it is the principle site of care for the inner city core population of Winnipeg. Patients included in this study were in-patients admitted to one of the three general internal medicine clinical teaching units. Patients admitted between April 1 and June 30, 1995 comprised the first three-month data set, and patients admitted between October 1 and December 31, 1995 comprised the second threemonth data set. The institution has subspecialty wards for neurology, leukemia and bone marrow transplant, chronic respiratory illness, cardiology, and rheumatology patients. Other medical patients are admitted, in rotation, to three general medical wards. Approximately $70 \%$ of patients are admitted to the CTU from the emergency department, with $15 \%$ transferred from other urban or rural institutions and 15\% admitted from out-patient clinics. There is a stringent antimicrobial utilization policy with components that include a controlled formulary and mandatory infectious diseases consultation for use of all high cost, parenteral antimicrobials. Verbal infectious dis- eases approval is required for less costly agents such as oral ciprofloxacin and parenteral cefotaxime.

Data collection: Patients were identified and enrolled prospectively at admission. Data were collected through record abstraction; patients were not directly approached to verify information. Tools used to assess patient characteristics included the Charlson comorbidity score as a measurement of underlying illness (2). This is a weighted index that takes into account the number and seriousness of comorbid diseases and has been shown to be a reliable estimator of death. A modified therapeutic intervention scoring system (TISS) score developed for general medical units was calculated for each admission as a measure of therapeutic interventions for care in the first $24 \mathrm{~h}$ (3). Laboratory use, medication use and consultations requested were recorded. Outcome data, including length of stay, complications during hospitalization, and death or discharge to the community or an alternative facility, were collected.

Definitions and statistical analysis: Patients were defined as admitted with infectious diseases if the ICD-9 code of the primary discharge diagnosis was identified as an active infection. A second group of patients were identified whose primary diagnosis was not an infectious disease, but who had infection as a secondary discharge diagnosis. Identification of infections developing during hospitalization used standard criteria for hospital-acquired infections (4). Two cases of peptic ulcer disease necessitating admission were not considered infectious diseases, and exacerbations of chronic obstructive pulmonary disease were considered infection only if the patient received antibiotics on admission.

Differences between patients hospitalized with infection, as either a primary or secondary diagnosis, and those hospitalized without infection were sought. $\chi^{2}$ analysis was used to test differences in categorical variables, and Student's $t$ test was used for continuous variables.

\section{RESULTS}

Infections at admission: Two hundred and eleven patients experienced 233 admissions in the first three-month period, and 200 patients experienced 209 admissions in the second period. In the first period, one-third of admissions had a primary diagnosis of infection; in the second period, one-quarter had a primary diagnosis of infection (Table 1). Pneumonia, urinary tract infection, and skin and soft tissue infections were the most common diagnoses, accounting for $59 \%$ and $56 \%$ of all admissions with a primary diagnosis of infection during periods 
TABLE 1

Admissions to a tertiary care general medical clinical teaching unit (CTU) for patients with a primary diagnosis of infection. Data collection was for April to June 1995 (period one) and October to December 1995 (period two)

\begin{tabular}{lcc}
\hline & \multicolumn{2}{c}{$\begin{array}{c}\text { Number of admissions (\% total) } \\
\text { [bacteremia] }\end{array}$} \\
& \multicolumn{1}{c}{ Period one } & Period two \\
\hline Total admissions/patients & $233 / 211$ & $209 / 200$ \\
Admissions for infection & $76 / 66(33 \% / 31 \%)$ & $52 / 48(25 \% / 24 \%)$ \\
Infections (\% admission) & & \\
Pneumonia & $21(9.0 \%) / 18$ & $18(8.6 \%)$ \\
Urinary infection & $10(4.3 \%)$ & $4(2.0 \%)[2]$ \\
Cellulitis & $9(3.9 \%)$ & $3(1.4 \%)[1]$ \\
Central line infection & $5(2.1 \%)[5]$ & $2(1.0 \%)[2]$ \\
Primary bacteremia & - & $1(0.5 \%)^{*}$ \\
Viral hepatitis & $2(0.9 \%)$ & $1(0.5 \%)$ \\
Acute gastroenteritis & $1(0.4 \%)$ & $2(1.0 \%)$ \\
Tuberculosis & $3(1.3 \%)$ & $2(1.0 \%)$ \\
Bacterial endocarditis & $3(1.3 \%)$ & $1(0.5 \%)$ \\
Foot infections & $5(2.1 \%)^{\dagger}$ & $4(1.9 \%)$ \\
AIDS & $8 / 3(3.4 \%)$ & $5 / 1(2.4 \%)$ \\
Clostridium difficile colitis & $3 / 1(1.3 \%)$ & - \\
Dengue & $1(0.4 \%)$ & - \\
Varicella zoster infection & $2(0.9 \%)$ & $1(0.5 \%)^{\ddagger}$ \\
Biliary tract infection & $1(0.4 \%)$ & $3(1.4 \%)[1]$ \\
COPD exacerbation & $2(0.9 \%)$ & $3(1.4 \%)$ \\
Supraglottic infection & - & $1(0.5 \%)$ \\
Ischiorectal abscess & - & $1(0.5 \%)[1]$ \\
\hline
\end{tabular}

*Klebsiella pneumoniae bacteremia in a patient with alcoholic cirrhosis; ${ }^{+}$Includes one blastomycosis; ${ }^{\ddagger}$ Ramsey-Hunt syndrome. COPD Chronic obstructive pulmonary disease

one and two. Many other infections, each accounting for only a small number of cases, also necessitated admission. Infection was present at admission but was not the primary diagnosis (Table 2 ) in $10 \%$ and $12 \%$ of admissions during the two periods, respectively. Pneumonia, urinary infection, and skin infections once again accounted for one-half to three-quarters of these cases. Thus, for the two study periods, $42 \%$ and $37 \%$ of patients admitted to the CTU were infected at admission.

Characteristics of patients with and without infections at admission: In the first period, patients who were admitted with infection were significantly younger but not in the second period (Table 3). The comorbidity score, however, was similar for infected and noninfected subjects. The Charlson score, which incorporates comorbidity and age, was not significantly
TABLE 2

Infections present at admission identified as secondary admitting diagnosis

\begin{tabular}{|c|c|c|}
\hline & \multicolumn{2}{|c|}{$\begin{array}{c}\text { Number of admissions (\% of total) } \\
\text { [bacteremia] }\end{array}$} \\
\hline & Period one & Period two \\
\hline Total admissions/patients & $23(10 \%) / 23(11 \%)$ & $24(12 \%) / 24(12 \%)$ \\
\hline Infections* & 26 & 27 \\
\hline Pneumonia & $3(1.3 \%)$ & $6(2.9 \%)$ \\
\hline Urinary infection & $4(1.7 \%)$ & $9(4.3 \%)$ \\
\hline Infected skin ulcers & $3(1.3 \%)$ & $5(2.4 \%)$ \\
\hline Bacteremia & $2(0.9 \%)[2]^{\dagger}$ & - \\
\hline Fungemia & $1(0.4 \%)[1]$ & - \\
\hline Candidiasis & $4(1.7 \%)$ & - \\
\hline Varicellar zoster infection & $1(0.4 \%)$ & $2(1.0 \%)$ \\
\hline Other $^{\ddagger}$ & $8(3.4 \%)^{\ddagger}$ & $5(2.4 \%)^{\S}$ \\
\hline
\end{tabular}

*Some admissions had more than one infection; ${ }^{\dagger}$ Alcoholic cirrhosis and hepatorenal syndrome (Staphylococcus aureus) and febrile neutropenia in non-Hodgkin's lymphoma (Pseudomonas species); ${ }^{*}$ Includes one patient each human immunodeficiency virus positive, endocarditis, epididymitis, herpes simplex infection, conjunctivitis, oral infection, ascending cholangitis and chronic obstructive pulmonary disease exacerbation; ${ }^{\S}$ Includes one patient each acute gastroenteritis, Clostridium difficile diarrhea, cellulitis, osteomyelitis and tuberculosis

different for the first (3.4 2.4 versus 4.2 2.5; $\mathrm{P}=0.09$ ) or second period (4.2 2.4 versus $4.62 .5 ; \mathrm{P}=0.62$ ) between patients admitted with and without infection (Table 3). Diabetic patients were no more likely to be admitted with infection than nondiabetic patients. Thus, 25 of 55 (45\%) admissions of diabetic patients in period one had infection compared with 74 of $178(42 \%)$ nondiabetic patients $(\mathrm{P}=0.72)$. In the second period, 16 of $50(32 \%)$ diabetic patients admitted had infection and 60 of $159(38 \%)$ without diabetes $(\mathrm{P}=0.57)$.

Patients admitted with infection consistently had higher TISS scores than those without (Table 3). There was no significant difference between patients admitted with a primary or secondary diagnosis of infection. When specific TISS components in the first $24 \mathrm{~h}$ of hospitalization were analyzed, in addition to differences in frequency of microbiological cultures, infected patients more frequently had an intravenous catheter (period one $74 \%$ versus $46 \%, \mathrm{P}<0.001$ and period two $81 \%$ versus $44 \%, \mathrm{P}<0.001)$ dressing changes (16\% versus $4.5 \%$, $\mathrm{P}=0.002 ; 21 \%$ versus $4.5, \mathrm{P}<0.001)$, and chest physiotherapy ( $12 \%$ versus $4.5 \%, \mathrm{P}=0.028 ; 11 \%$ versus $3 \%, \mathrm{P}=0.023)$. Infected patients were significantly less likely to be receiving

TABLE 3

Measures of comorbidity, interventions and length of stay of patients admitted with or without infection

\begin{tabular}{|c|c|c|c|c|c|c|}
\hline \multirow[b]{2}{*}{ Infected at admission } & \multicolumn{2}{|c|}{ Period one } & \multicolumn{4}{|c|}{ Period two } \\
\hline & No & Yes & $\mathbf{P}$ & No & Yes & $\mathbf{P}$ \\
\hline Age & $61.4 \quad 19.5$ & 52.917 .33 & 0.001 & 64.119 .8 & 58.920 .2 & 0.11 \\
\hline Comorbidity & 2.31 .85 & 2.21 .9 & 0.55 & 2.31 .8 & 2.61 .8 & 0.54 \\
\hline $\begin{array}{l}\text { Therapeutic intervention scoring } \\
\text { system }\end{array}$ & 9.615 .08 & 10.624 .92 & 0.09 & $9.94 \quad 6.1$ & $12.07 \quad 4.98$ & 0.01 \\
\hline Length of stay (median) & $17.627 .9(9)$ & $12.319 .9(7)$ & 0.06 & $16.628 .2(10)$ & $15.316 .7(12)$ & 0.40 \\
\hline
\end{tabular}


TABLE 4

Medication costs and consultations for admissions with patients infected or not at admission

\begin{tabular}{|c|c|c|c|c|c|c|}
\hline \multicolumn{7}{|c|}{ Median (range) } \\
\hline & \multicolumn{2}{|c|}{ Period one } & \multicolumn{3}{|c|}{ Period two } & \multirow[b]{2}{*}{$\mathbf{P}$} \\
\hline & Infected $(n=99)$ & Not infected $(n=134)$ & $\mathbf{P}$ & Infected $(n=76)$ & Not infected $(n=133)$ & \\
\hline Antimicrobials & $70.38(0-5,146.26)$ & $0(0-443.08)$ & $<0.001$ & $69.39(0-2,421.31)$ & $0(0-962.13)$ & $<0.001$ \\
\hline Not antimicrobials & $23.00(0-4,946.00)$ & $46.00(0.10-4,427.65)$ & 0.002 & $46.50(0-1,403.00)$ & $43.00(0-4,458.00)$ & 0.59 \\
\hline Infectious diseases & $40(40)^{*}$ & $6(4.5)$ & $<0.001$ & $22(28.9)$ & $8(6.0)$ & $<0.001$ \\
\hline Cardiology & $5(5.1)$ & $21(15.7)$ & 0.01 & $7(9.0)$ & $24(18.0)$ & 0.08 \\
\hline Respiratory & $11(11)$ & $6(4.5)$ & 0.05 & $13(17.1)$ & $8(6.0)$ & 0.01 \\
\hline Gastroenterology & $14(14)$ & $13(9.7)$ & 0.30 & $7(9.2)$ & $15(11.3)$ & 0.64 \\
\hline Geriatrics & $2(2.0)$ & $6(4.5)$ & 0.34 & $7(9.2)$ & $19(14.3)$ & 0.28 \\
\hline
\end{tabular}

*Number in parentheses is the percentage of episodes

TABLE 5

Infections acquired during hospitalization

\begin{tabular}{|c|c|c|}
\hline & \multicolumn{2}{|c|}{ Number (\%) admissions [bacteremia] } \\
\hline & Period one & Period two \\
\hline Infections/patient & $19(8.2 \%) / 18$ & $16(7.7 \%) / 15$ \\
\hline Pneumonia & $8(3.4 \%)[1]$ & $6(2.6 \%)[2]$ \\
\hline Urinary infection & $5(2.1 \%)$ & $1(0.5 \%)$ \\
\hline Bacterial peritonitis & - & $2(1.0 \%)$ \\
\hline Infected skin ulcers & $3(1.3 \%)$ & $1(0.5 \%)$ \\
\hline Other skin/soft tissue & $2(0.9 \%)$ & $3(1.4 \%)[1]$ \\
\hline Local infection/line site & $1(0.4 \%)$ & $1(0.5 \%)$ \\
\hline Postoperative infection & - & $2(1.0 \%)^{*}$ \\
\hline
\end{tabular}

*Two infected leg amputation sites

oral ( $4 \%$ versus $13.4 \%, \mathrm{P}=0.001 ; 3.9 \%$ versus $13 \%, \mathrm{P}=0.037$ ) or intravenous anticoagulant therapy $(5.1 \%$ versus $18 \%$, $\mathrm{P}=0.002 ; 9.2 \%$ versus $27 \%, \mathrm{P}=0.002$ ). In period one only, infected patients were significantly less likely to have an indwelling urinary catheter ( $13 \%$ versus $30 \%, \mathrm{P}=0.002)$. Indwelling catheter use was similar between groups for the second period ( $25 \%$ and $25 \%)$.

Laboratory tests, medications and consultations: Frequency of use of 75 biochemical, hematological, microbiological and radiological tests throughout the ward stay was compared between infected and noninfected admissions. As expected, significant differences in microbiological testing were observed for one or both periods for sputum, blood, wound and stool culture, viral serology, Mantoux 5TU, and human immunodeficiency virus (HIV) testing. The rate of urine culture testing was similar for infected and noninfected patients. Tests performed significantly less frequently in infected patients included creatine kinase $(\mathrm{CK})$, creatine kinase myocardial enzyme, calcium, phosphate, potassium, prothrombin time, partial prothrombin time, electrocardiogram (EKG), echocardiogram and angiography.
The total number of medications received did not differ for patients admitted with or without infection. For period one, the median number of patients admitted was nine for infected and 10 for noninfected patients, and, for period two, 10 and nine, respectively. However, the total medication costs were consistently greater for patients admitted with infection (Table 4). The increased medication costs were entirely accounted for by costs for antimicrobial therapy.

The median number of physician consultations was one (range zero to nine) for infected patients in period one and two (range zero to nine) for period two. For noninfected admissions, the median number was one for both periods (Table 4). Infectious diseases was the most frequent medical consultation in the first period $(n=46)$, followed by cardiology $(n=26)$, gastroenterology $(n=27)$ and nephrology $(n=26)$. In the second period, cardiology $(n=31)$ was the most frequent consultation followed by infectious diseases $(n=30)$, nephrology $(n=29)$, geriatrics $(n=26)$, respiratory medicine $(n=21)$ and gastroenterology $(n=22)$. Consultations to both infectious diseases and respiratory medicine occurred significantly more frequently for patients admitted with infection. Cardiology and coronary care unit consultation occurred significantly less frequently. All other physician consultations were similar between infected and noninfected patients.

Antimicrobial therapy: One hundred forty-one admissions in the first three-month period $(60 \%)$ received antimicrobial therapy, and 124 (59\%) admissions in the second. Intravenous antimicrobials were given to 108 (45\%) in the first study period and $89(43 \%)$ in the second study period. For patients with infection identified at admission, 89 (88\%) and 69 (91\%) received antimicrobials. Additionally, 12 of 13 (92\%) and 12 of 12 $(100 \%)$ with hospital-acquired infection received antimicrobial therapy. Cefuroxime, given in 39 admissions in the first period and 31 in the second, was the most frequent intravenous antimicrobial, followed by gentamicin (27 and 22), cloxacillin (23 and 19), cefazolin (21 and 17), ampicillin (17 and 21) and erythromycin (14 and 21). Other antimicrobials for which over 
10 admissions had courses of therapy prescribed during either period included cefotaxime, clindamycin and vancomycin. The most frequent oral antimicrobials were trimethoprim/sulfamethoxazole (37 and 36), metronidazole (14 and 14) and ampicillin (10 and 11).

Thirty-eight patients (31\%) in the first period and 43 (35\%) patients in the second period with no infectious diagnosis received antimicrobial therapy. Of these, $12(32 \%)$ and $10(23 \%)$ antimicrobial courses were periprocedure prophylaxis. Most of the remainder were short courses of empirical antimicrobials given early in the admission, presumably while an infectious diagnosis was being excluded, or continuous antimicrobial therapy for diverticulosis, inflammatory bowel disease, hepatic encephalopathy or obstructive uropathy.

Outcomes: Eighteen $(8.5 \%)$ admissions in the first period and $15(7.2 \%)$ in the second had infections identified as complications that developed during hospitalization (Table 5). Hospital-acquired infection occurred with equal frequency in patients admitted (seven [8.0\%]) and not admitted (11 [9.0\%]) with infection in period one and period two (four [5.6\%]) and (11 [8.6\%]). The rate of hospital-acquired infections on the CTUs was 5.3/1000 patient days and 4.7/1000 patient days during the two study periods. Acquisition of hospital-acquired infections was 5.3/1000 patient days and 3.4/1000 patient days for subjects with infection at admission, and 5.3/1000 and 5.7/1000 days for those without infection. The differences were not significant.

The length of stay was similar for patients admitted with infections, whether as primary or secondary diagnosis, and other admissions (Table 3). There were 13 (5.6\% of admissions) deaths during the first three months and $25(12 \%)$ during the second $(\mathrm{P}=0.027)$. Of these, two $(15 \%)$ in the first period and five $(20 \%)$ in the second were deaths due to infection. Four of $128(3.1 \%)$ admissions with patients infected at admission died of the admitting infection, and three of 314 $(1.0 \%)$ not admitted with infection died of hospital-acquired infection. These deaths from infection included the deaths of two AIDS patients, one with Pneumocystis carinii pneumonia and one with tuberculosis, four patients with pneumonia, one each with underlying multiple sclerosis, chronic lymphocytic leukemia and cerebrovascular accident, one 95-year old, and one patient with bacterial peritonitis. Thus, infection was a minor contributor to death in patients on the general wards.

\section{DISCUSSION}

This review has focused on issues related to infections and characteristics of patients with infections on general internal medical teaching wards. The institution in which the general internal medicine ward was located is a tertiary care teaching hospital, and patients on this ward had a high acuity of illness. These observations then are relevant to hospitals and wards with a patient population with similar characteristics. They should not be assumed to be similar in community or other institutions that chiefly provide secondary care.

Infections are one of the most frequent problems contributing to hospitalization on general medical wards. About onequarter of patients were admitted for infection, and a further
$10 \%$ had infection at admission, but infection was not the primary diagnosis. The most frequent types of infection were pneumonia, urinary infection and cellulitis. These three diagnoses, however, accounted for only about $50 \%$ of patients admitted with infection. A large variety of other types of infection, each identified infrequently, comprised the remainder. HIV infection was an uncommon reason for hospitalization, reflecting the low local prevalence and incidence of this disease in the referral population (5).

Nosocomial infection occurred in only a small proportion of patients. The most important nosocomial infections were the same as the most frequent admitting infectious diagnoses, ie, pneumonia, urinary tract infection, and skin and soft tissue infections. The acquisition of hospital-acquired infection was similar whether a patient had infection at admission or not. Infection was also an infrequent cause of death on the general medical unit. When death from infection did occur, most cases were attributable to HIV infection or pneumonia in debilitated subjects.

Some relatively minor differences were observed between patients with or without infection at admission. Patients with infection tended to be younger and required significantly more interventions in the first $24 \mathrm{~h}$. The increased interventions early in hospitalization related to infectious disease management, and included diagnostic microbiology tests, wound care and parenteral antimicrobials. Overall, however, use of laboratory and diagnostic tests during hospitalization was similar for subjects admitted with or without infection. While interventions for the management of infection were increased in infected patients, this group had fewer cardiology interventions. Use of physician consultation was also similar for the two groups, although variation in the subspecialty of consultation was, as expected, observed. Infected and noninfected patients had similar mortality and lengths of stay.

There was intense antimicrobial use in patients admitted to the general medical unit. The one consistent and important difference between the infected and noninfected groups of patients was the greater cost for pharmaceuticals in the infected group. Antimicrobial costs were entirely responsible for the substantial difference between the two groups. While the use of antimicrobials in patients infected at admission or who acquired infection in hospital seems appropriate, almost $30 \%$ of patients who did not have any documented infection at admission received antimicrobial therapy. Some of this antimicrobial use is explained by the $5 \%$ to $10 \%$ of subjects with hospital-acquired infection. The reasons for the remaining courses included perioperative prophylaxis, initial empirical coverage for possible infection and prolonged therapy for selected diseases. In fact, the majority of antimicrobial courses given to the $30 \%$ of noninfected patients appeared appropriate.

Infectious diseases was one of the most frequent medical subspecialties consulted on the general medical ward. There was some variation in consultation frequency between the two periods; however, $30 \%$ to $40 \%$ of infected patients had consultations, and $20 \%$ and $14 \%$ of all patients admitted had infectious diseases consultation. Unfortunately, this review 
does not allow us to address the important issue of the contribution of infectious diseases consultation to antimicrobial use or patient outcomes.

\section{CONCLUSIONS}

Patients admitted with infections are a large proportion of patients on general medical wards. Resident trainees on a general medical ward are exposed to a large number and wide spectrum of patients with infections. A relatively small number of patients acquire infection in hospital, and acquisition of infection in hospital is not associated with the presence of infection at admission. The major differentiating feature of patients admitted with infections compared with those without is the increased medication costs attributable to antibiotic use. Efforts to enhance hospital utilization would be most efficiently focused on the three major categories of infection: pneumonia, urinary infection, and skin and soft tissue infection. The utilization of antimicrobials on the general medical wards should be more fully explored.

\section{REFERENCES}

1. Maudsley RF. The clinical teaching unit in transition. Can Med Assoc J 1993;148:1564-6.

2. Charlson ME, Pompu P, Ales KL, MacKenzie CR. A new method of classifying prognostic comorbidity in longitudinal studies. Development and validation. J Chronic Dis 1987;40:373-83.

3. Cullen DJ, Nemeskal AR, Zaskavsky AM. Intermediate TISS: A new therapeutic intervention scoring system for non-ICU patients. Crit Care Med 1994;22:1406-11.

4. Garner JS, Jarvis WR, Emori TG, Horan TC, Hughes JM. CDC definitions for nosocomial infections, 1988. Am J Infect Control 1988;16:28-40.

5. Health Canada, Division of HIIV/AIDS Surveillance, Bureau of HIV/AIDS and STD, Laboratory Centre for Disease Control, April 1996. Quarterly Surveillance Update: AIDS in Canada. Ottawa: Health Canada, 1996. 


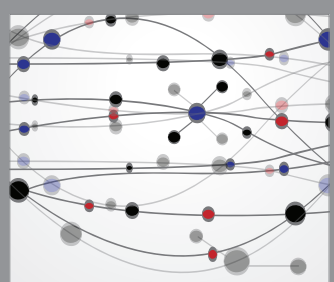

The Scientific World Journal
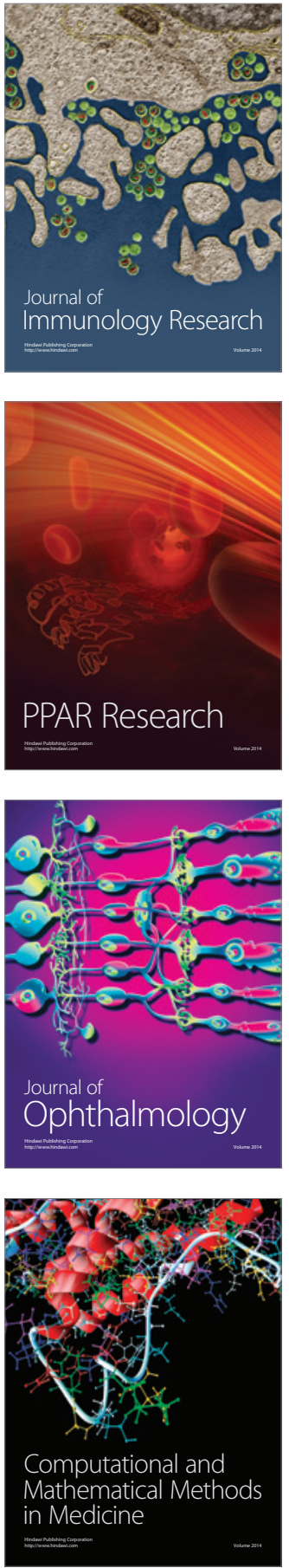

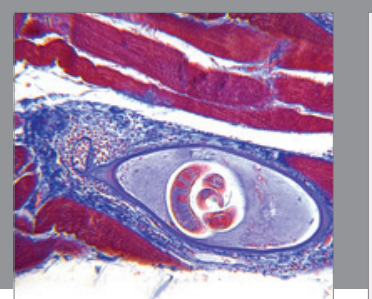

Gastroenterology Research and Practice

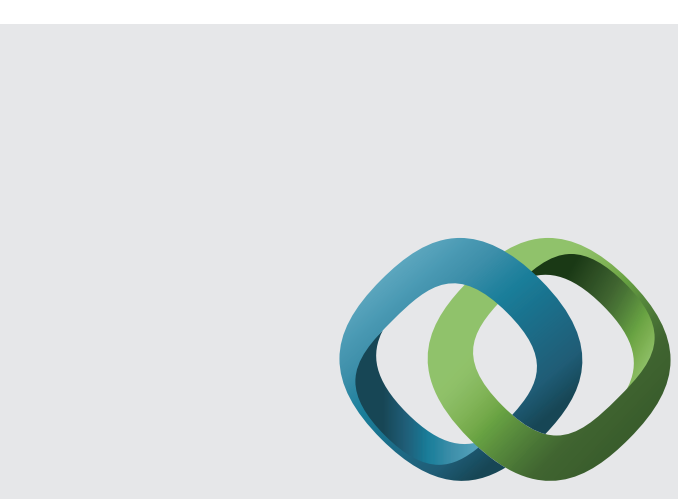

\section{Hindawi}

Submit your manuscripts at

http://www.hindawi.com
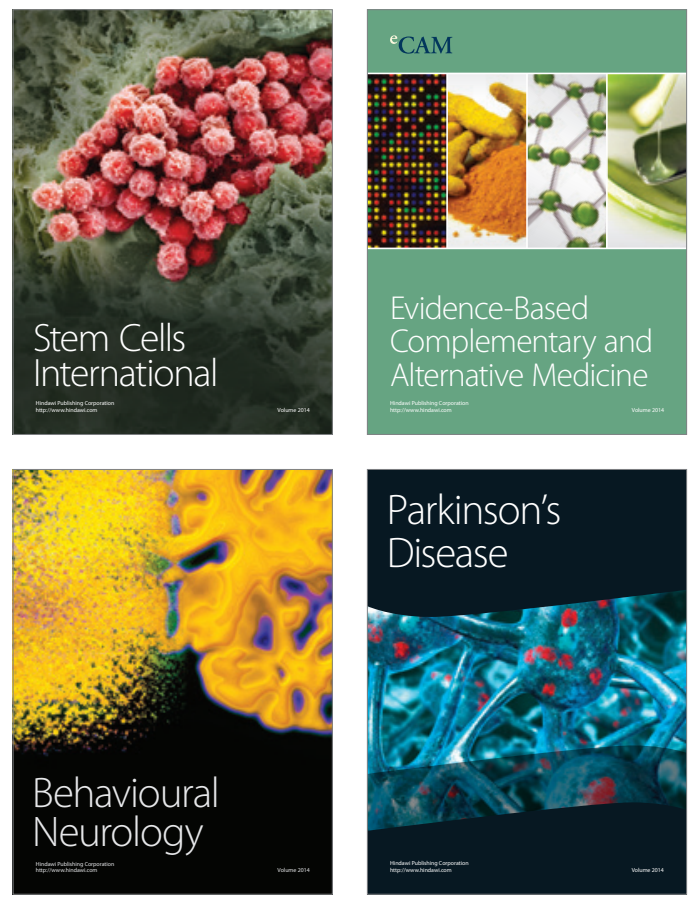
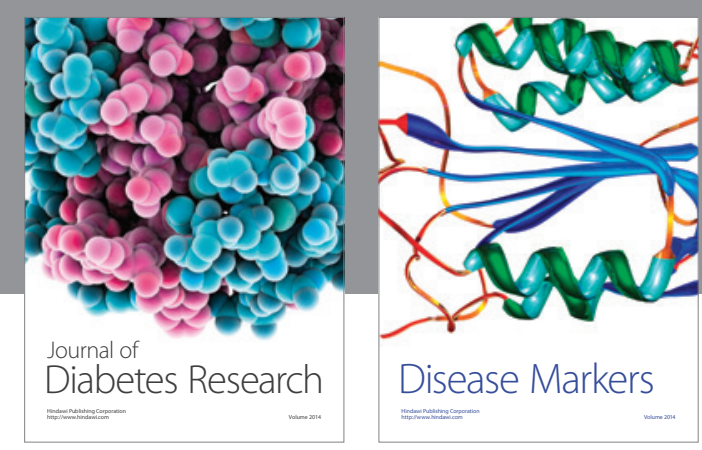

Disease Markers
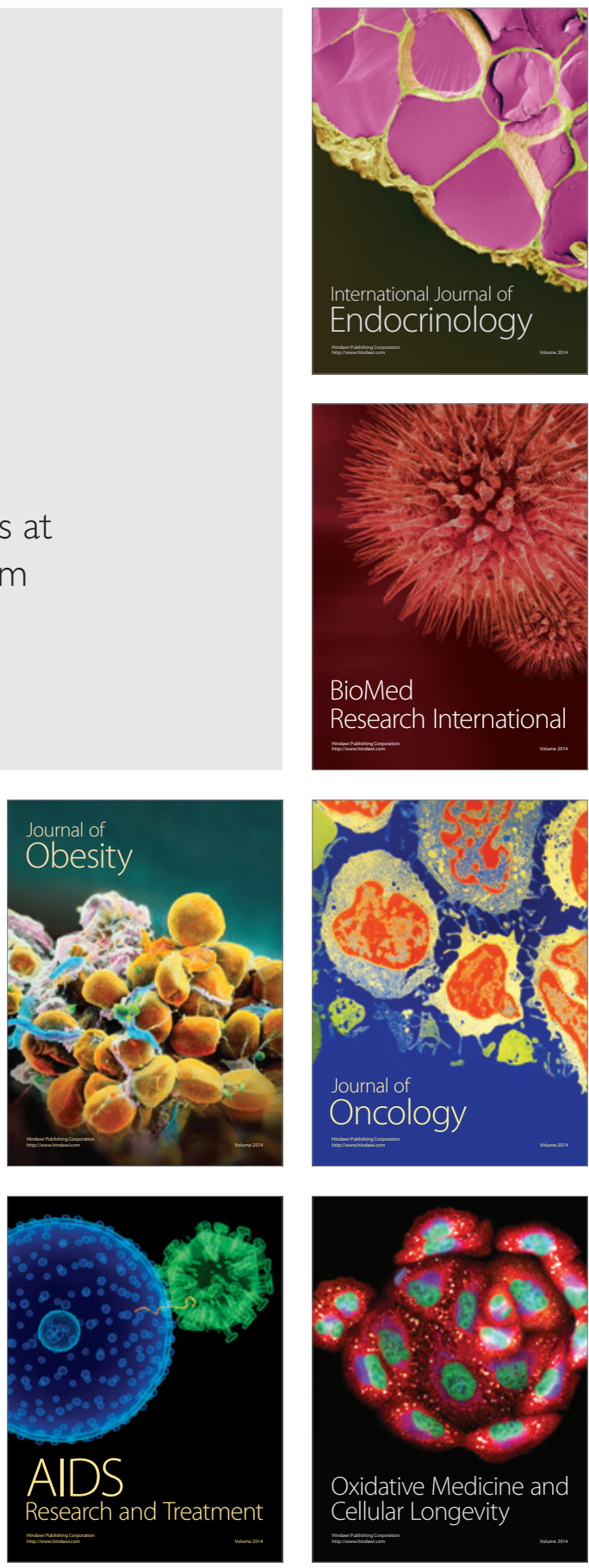